\title{
HYPERINFLATION OF CANINE LUNG ALLOGRAFTS DURING STORAGE INCREASES REPERFUSION PULMONARY EDEMA
}

Motoi Aoe, MD

Kan Okabayashi, MD

Joel D. Cooper, MD, FRCS(C)

G. Alexander Patterson, MD, $\operatorname{FRCS}(\mathrm{C})$
The optimal state of inflation for lung allografts during preservation is not known. We previously showed that hyperinflation of canine lung allografts during storage improved posttransplant graft function as measured during 10 minutes of contralateral pulmonary artery occlusion. However, we have also shown that hyperinflation during storage increases pulmonary capillary permeability. It is possible that short-term total cardiac perfusion through the transplanted left lung (for assessment) may not adequately reproduce the clinical situation. The purpose of this study was to assess the effects of hyperinflation during storage in a canine left single-lung transplantation model in which all perfusion was continuously directed to the graft after implantation. Twenty canine left single-lung transplants were done. The lungs of donor animals were ventilated at a tidal volume of $750 \mathrm{ml}$ and an inspired oxygen fraction of 100\%. Donor lungs were flushed with modified Euro-Collins solution and the trachea occluded at end inspiration. For donors in groups I and III, the trachea was sealed at that postinflation volume. In groups II and IV, $200 \mathrm{cc}$ of air was withdrawn from the endotracheal tube under positive pressure and the trachea sealed at the lower tidal volume. Lungs were then extracted and stored at $1^{\circ} \mathrm{C}$ for 12 hours. After the preservation period, left lung transplants were performed. After implantation in all groups, the right pulmonary artery was ligated. In groups I and II, the right bronchus was ligated and in groups III and IV the right bronchus was kept open. Subsequent allograft gas exchange and hemodynamics were assessed during a 6-hour period of reperfusion. After assessment, both lungs were excised, wet/dry lung weight ratio was calculated, and histologic examination was done. During the 6-hour assessment, lungs stored in a state of hyperinflation (groups I and III) showed rapid deterioration of gas exchange. At the final assessment, arterial oxygen tension and alveolar-arterial oxygen gradient of groups I and III were significantly worse than those of groups II and IV (group I versus group II: arterial oxygen tension $87.5 \pm 15.0$ versus $373.8 \pm 65.5 \mathrm{~mm} \mathrm{Hg}$, alveolararterial oxygen gradient $564.4 \pm 13.2$ versus $298.6 \pm 69.3 \mathrm{~mm} \mathrm{Hg}, p<0.05$; group III versus group IV: arterial oxygen tension $245.4 \pm 33.0$ versus 543.6 \pm $41.8 \mathrm{~mm} \mathrm{Hg}$, alveolar-arterial oxygen gradient $392.5 \pm 35.6$ versus $120.5 \pm 34.7$ $\mathrm{mm} \mathrm{Hg}, p<0.01$ ). We conclude that donor lung hyperinflation during storage does not provide better posttransplant allograft function when perfusion is limited only to the allograft. (J Thorac Cardiovase Surg 1996;112:94-102)
From the Division of Cardiothoracic Surgery, Department of Surgery, Barnes Hospital, Washington University School of Medicine, St. Louis, Mo.

Supported by National Institutes of Health grant 1 R01 HL41281.

Received for publication Oct. 10, 1995; accepted for publication Nov. 21, 1995.

Address for reprints: G. Alexander Patterson, MD, Suite 3108, Queeny Tower, One Barnes Hospital Plaza, St. Louis, MO 63110.

Copyright (C) 1996 by Mosby-Year Book, Inc.

$0022-5223 / 96 \$ 5.00+0 \quad \mathbf{1 2 / 1 / 7 0 7 9 0}$ $\triangle$ lthough clinical lung transplantation has recently Abecome an accepted therapy for end-stage pulmonary diseases, ${ }^{1}$ early graft dysfunction remains a common and highly unpredictable problem. Numerous studies have been conducted in an effort to establish the optimal strategy for pulmonary allograft preservation. The optimal state of inflation or ventilation during lung preservation remains uncertain.

Homatas, Bryant, and Eiseman ${ }^{2}$ demonstrated 
that continuous positive-pressure ventilation improved warm ischemic tolerance of the lung. Veith and associates ${ }^{3}$ reported that a single lung could maintain adequate pulmonary function after 3 hours of normothermic ischemia if it was inflated or after 2 hours of ischemia if it was ventilated, whereas a deflated lung failed to provide adequate pulmonary function within a 1-hour ischemic period. Furthermore, Fonkalsrud and colleagues ${ }^{4,5}$ revealed that lung expansion by positive end-expiratory pressure or static inflation with $10 \mathrm{~cm}$ water pressure maintained excellent pulmonary function in lungs after 4 to 10 hours of normothermic ischemia. Despite these results, in 1988, Todd and associates ${ }^{6}$ published a technique for harvesting atelectatic left lung allografts, which was successfully used in the early experience of the Toronto group. In contrast, Puskas and associates ${ }^{7}$ reported that the combination of large tidal volume and positive end-expiratory pressure during pulmonary flushing and hyperinflation during storage provided excellent early posttransplantation pulmonary function in a canine allotransplantation model.

In a previous study with use of a long-term canine left single-lung allotransplantation model in which graft function was assessed by brief 10-minute periods of contralateral pulmonary artery (PA) cuff occlusion, we demonstrated that donor hyperinflation improves posttransplant lung allograft function unpublished data. ${ }^{*}$ Furthermore, we suggested that this improvement could be attributed to the maintenance of lower alveolar surface tension during storage in hyperinflated grafts. However, previous reports have demonstrated that high airway pressure produces pulmonary edema. ${ }^{8-11}$ Furthermore, recent work from our laboratory indicates that hyperinflation during storage increases pulmonary capillary filtration coefficient. ${ }^{12}$ Finally, experience in our clinical lung transplant program suggests that hyperinflation results in a higher prevalence of immediate allograft dysfunction because of pulmonary edema. Our previous conflicting results that suggested that hyperinflation was beneficial might be explained by the brief 10-minute period of contralateral PA occlusion for allograft assessment used in that experimental model. Such a short period of total perfusion to the allograft might not have been long enough to demonstrate physiologic effects of hyperinflation-induced pulmonary capillary permeability.

*Aoe M, Trachiotis GD, Manchester JK, et al. Effects of hyperinflation during storage in lung transplantation.
The purpose of the present study was to reevaluate the effects of hyperinflation on posttransplant graft function by using a model in which the transplanted lung receives the entire cardiac output.

\section{Material and methods}

Donor procedure. Forty adult mongrel dogs (body weight 24.2 to $30.4 \mathrm{~kg}$ ) that served as donors and recipients were paired by weight and randomly assigned to one of four study groups $(n=5)$. Donor lung excision and storage were done by previously described techniques (Aoe and colleagues, unpublished data). The donors were anesthetized with sodium thiopental $10 \mathrm{mg} / \mathrm{kg}$ intravenously, followed by atropine $0.04 \mathrm{mg} / \mathrm{kg}$ intramuscularly, and intubated with a $9.0 \mathrm{~F}$ special endotracheal tube to monitor intratracheal air pressure throughout the harvest procedure by means of a model $1290 \mathrm{~A}$ transducer (Hewlett-Packard, Andover, Mass.). The lungs were ventilated with a tidal volume of $750 \mathrm{ml}$ (approximately 35 $\mathrm{ml} / \mathrm{kg}$ ), a respiratory rate of 12 breaths $/ \mathrm{min}$, an inspired oxygen fraction of 1.0 , and no positive end-expiratory pressure (Bennett MA1, Puritan Bennett, Inc., Overland Park, Kan.). The femoral artery was cannulated to monitor systemic arterial pressure during the harvest procedure.

After a median sternotomy, the thymus was removed and the azygos vein was divided. Both venae cavae and the aorta, PA, and trachea were isolated. Heparin $(400 \mathrm{U} / \mathrm{kg})$ was administered systemically and a $6.5 \mathrm{~mm}$ curved metaltipped perfusion cannula (Sarns, Inc., Ann Arbor, Mich.) was inserted into the main PA just distal to the valve, secured with a purse-string suture, and connected by means of tubing to a bag of cold $\left(1^{\circ} \mathrm{C}\right)$ modified EuroCollins solution $(4 \mathrm{mmol} / \mathrm{L} \mathrm{MaSO}$ and $32.7 \mathrm{gm} / \mathrm{L}$ glucose added to the original Euro-Collins solution), which was hung at a height of $40 \mathrm{~cm}$ above the chest. After four 1600 $\mathrm{ml}$ tidal volume breaths were administered to eliminate atelectasis, the previous ventilatory parameters were resumed for 1 minute to allow the lungs to reach their baseline volume. Cardiac inflow occlusion was then accomplished by ligation of both venae cavae.

The left atrial appendage was amputated and the lungs were flushed by gravity pressure $\left(40 \mathrm{~cm} \mathrm{H}_{2} \mathrm{O}\right)$ with 50 $\mathrm{ml} / \mathrm{kg}$ of Euro-Collins solution. Simultaneous topical cooling was achieved by intrathoracic immersion of the lungs in cold saline solution $\left(1^{\circ}\right.$ to $\left.4^{\circ} \mathrm{C}\right)$. After completion of the flush, the endotracheal tube was clamped at end-inspiration and the intratracheal air pressure was recorded on a Gould 2800 series recorder (Gould Inc., Cleveland, Ohio). At this point, animals were divided into two groups. In groups I $(n=5)$ and III $(n=5)$, no air was withdrawn and the trachea was stapled. In groups II $(n=5)$ and IV $(n=$ $5), 200 \mathrm{ml}$ of air was withdrawn gently through the tracheal tube under positive intratracheal pressure (Table I). Intratracheal pressure was measured again and the trachea was stapled. The heart-lung block was then excised, placed in a plastic bag containing $1^{\circ} \mathrm{C}$ Euro-Collins solution, and preserved at $1^{\circ} \mathrm{C}$ for 12 hours.

Recipient procedure. Left single-lung implantation was done in the usual fashion. Twenty adult mongrel dogs (body weight 25.1 to $31.7 \mathrm{~kg}$ ) were anesthetized in the 
Table I. Characteristics of experimental groups

\begin{tabular}{|c|c|c|c|c|c|c|c|c|c|}
\hline Group & $\begin{array}{l}\text { Hypenventilation } \\
\text { during } \\
\text { flushing }\end{array}$ & $\underset{\text { withdrawal }}{\text { Air }}$ & $\begin{array}{l}\text { Flushing } \\
\text { time (sec) }\end{array}$ & $\begin{array}{l}\text { Flushing } \\
\text { pressure } \\
(\mathrm{mm} \mathrm{Hg})\end{array}$ & $\begin{array}{l}\text { Excision } \\
\text { time (min) }\end{array}$ & $\begin{array}{l}\text { Implantation } \\
\text { time (min) }\end{array}$ & $\begin{array}{c}\text { Total } \\
\text { ischemic time } \\
(h r \pm \text { min })\end{array}$ & $\begin{array}{c}\text { Rt. PA } \\
\text { ligation } \\
\text { during } \\
\text { assessment }\end{array}$ & $\begin{array}{l}\text { Rt. bronchus } \\
\text { ligation } \\
\text { during } \\
\text { assessment }\end{array}$ \\
\hline I & + & - & $70 \pm 6.3$ & $17.8 \pm 0.6$ & $10.2 \pm 0.7$ & $61.8 \pm 3.9$ & $12.1 \pm 9$ & + & + \\
\hline II & + & + & $77 \pm 7.7$ & $20.6 \pm 1.7$ & $11.2 \pm 0.5$ & $58.6 \pm 1.2$ & $11.9 \pm 6$ & + & + \\
\hline III & + & - & $74 \pm 9.2$ & $18.6 \pm 1.0$ & $9.8 \pm 1.1$ & $59.8 \pm 3.3$ & $12.0 \pm 10$ & + & - \\
\hline IV & + & + & $65 \pm 7.4$ & $19.0 \pm 1.2$ & $11.2 \pm 2.5$ & $57.2 \pm 2.3$ & $11.8 \pm 4$ & + & - \\
\hline
\end{tabular}

There were no significant differences between groups in flushing time, flushing pressure, excision time, implantation time, or total ischemic time. Hyperventilation, Lungs were ventilated with tidal volume of $750 \mathrm{ml}, 20$ breaths $/ \mathrm{min}$, and positive end-expiratory pressure $0 \mathrm{~cm} \mathrm{H}_{2} \mathrm{O}$; excision time, from flushing finish to immersion in storage solution; total ischemic time, from inflow occlusion to start reperfusion; Rt.PA, right PA.

same manner as in the donor procedure and the lungs ventilated with an adjustable-rate Harvard pump respirator (model 613, Harvard Apparatus, South Natick, Mass.) with $98.5 \%$ oxygen and $1.5 \%$ halothane. Systemic, main $\mathrm{PA}$, and central venous pressures were obtained through a femoral arterial cannula and a balloon-tipped catheter (Swan-Ganz catheter, Baxter Healthcare Corp., Edwards Division, Santa Ana, Calif.) by means of a transducer (model 1290A, Hewlett-Packard). A thoracotomy was done in the left fifth intercostal space and a left pneumonectomy was done. In groups I and II, the right PA and the right upper and lower bronchis were mobilized through the mediastinum, and umbilical tapes were placed around them to obtain left single-lung perfusion and ventilation during assessment. In groups III and IV, only the right PA was mobilized. The left lung of the donor was trimmed from the heart-lung block in a basin containing cold saline solution. The left lung was covered with cold gauze during implantation. The left atrial and pulmonary arteries and bronchus were anastomosed consecutively. A continuous everting mattress suture was used for the left atrial anastomosis, and continuous over-and-over suture was used for the other two anastomoses.

After the completion of anastomoses, the left transplanted lung was inflated with $30 \mathrm{~cm}$ of water pressure once and ventilation and reperfusion were started. A Millar Mikro-Tip catheter pressure transducer (model SPC-370, Millar Instruments Inc., Houston, Tex.) was introduced through the mediastinal pulmonary vein into the left atrium and anchored. Two chest tubes were placed, connected to a waterseal bottle, and placed at -15 $\mathrm{cm} \mathrm{H}_{2} \mathrm{O}$ pressure. In groups I and II, the right upper and lower bronchi were both individually ligated. Complete occlusion of the right-sided airway was confirmed by examination with a fiberoptic bronchoscope. At the same time, the right PA in all the groups was ligated. Thus the transplanted left lung received the total cardiac output in all groups.

In groups I and II only the transplanted lung was ventilated (Bennett model MA1, tidal volume $550 \mathrm{ml}$, respiratory rate 20 breaths/min, fraction of inspired oxygen 1.0 , and $5 \mathrm{~cm} \mathrm{H}_{2} \mathrm{O}$ positive end-expiratory pressure). In groups III and IV, both lungs were ventilated (Bennett model MA1, tidal volume $750 \mathrm{ml}$, respiratory rate 20 breaths $/ \mathrm{min}$, fraction of inspired oxygen 1.0 , and $5 \mathrm{~cm}$ $\mathrm{H}_{2} \mathrm{O}$ positive end-expiratory pressure (Table I). We chose to include these two groups (that is, both lungs ventilated) so as to create a situation comparable with that in our previous studies in which postimplantation allograft function had been assessed with both the native and transplanted lungs ventilated. Peak inspiratory pressures were recorded. The chest wall was then closed and animals turned to the supine position.

Assessment of lung function. During the 6-hour assessment period, the level of anesthesia was maintained with periodic administration of intravenous sodium thiopental. Aortic, PA, central venous, and left atrial pressures were continuously recorded. Arterial and central venous blood gas values were analyzed every 15 minutes from the start of the assessment. Cardiac output was determined in triplicate by the thermodilution method every hour. Blood $\mathrm{pH}$ was normalized as necessary by administration of bicarbonate. Ringer's lactate solution was judiciously infused to maintain central venous pressure within a normal range. Edema fluid from the left lung was suctioned with a fiberoptic bronchoscope 10 minutes before each assessment. Total edema fluid volume aspirated during the assessment was measured. After the assessment, the animals were killed and both lungs were excised for pathologic study and wet/dry lung weight ratio measurement.

Statistical analysis. All data are represented as mean plus or minus standard error of the mean. One-way analysis of variance (ANOVA) with repeated measures was used to determine whether an overall difference existed in graft function between the groups during the assessment. Additional comparison was done to determine where significant differences arose during the assessment. The other data were analyzed with one-way ANOVA. Statistical significance was accepted at $95 \%$ confidence limit, $p<0.05$.

All animals received humane care in compliance with the "Principles of Laboratory Animal Care" formulated by the National Society for Medical Research and the "Guide for the Care and Use of Laboratory Animals" prepared by the National Academy of Science and published by the National Institutes of Health (NIH Publication No. 86-23, revised 1985).

\section{Results}

There were no significant differences in mean weight of donor and recipient dogs, flushing times, flushing pressures, excision times, implantation 


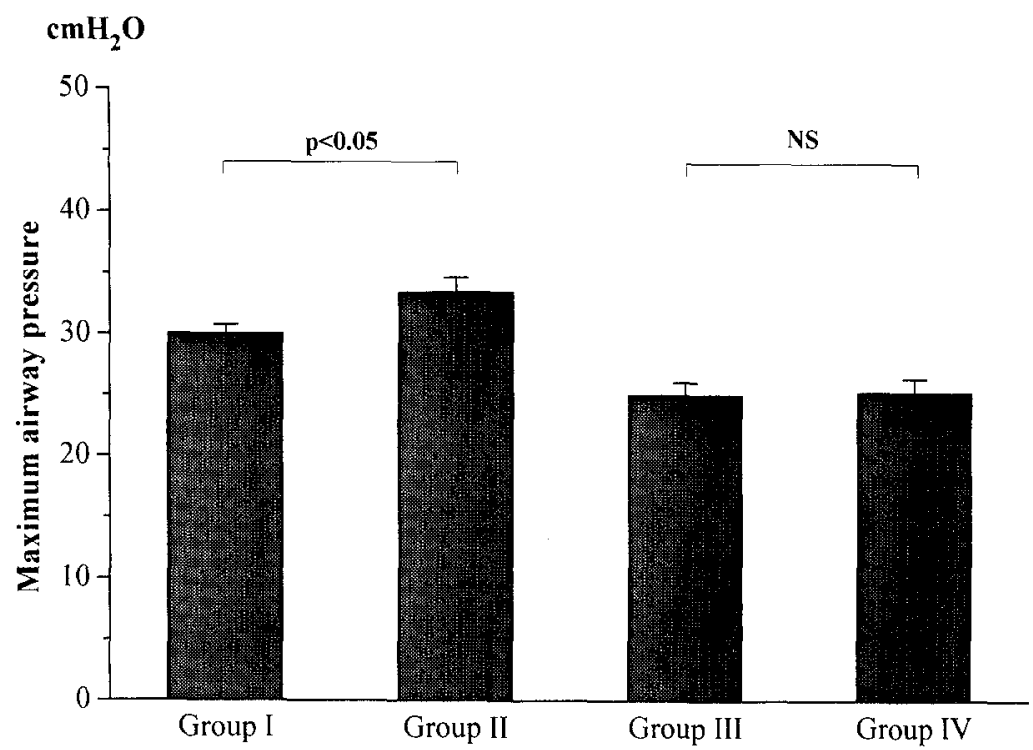

Fig. 1. Maximum airway pressure just before chest closure. Maximum airway pressure in group I was significantly lower than that in group II $(p<0.05)$, but there was no significant difference between groups III and IV. NS, Not significant.

Table II. Airway pressure during harvest

\begin{tabular}{|c|c|c|c|c|}
\hline \multirow[b]{2}{*}{ Group } & \multicolumn{4}{|c|}{ Pressure $(\mathrm{mm} \mathrm{Hg})$} \\
\hline & $\begin{array}{l}\text { Before } \\
\text { flushing }\end{array}$ & $\begin{array}{l}\text { During } \\
\text { flushing }\end{array}$ & $\begin{array}{l}\text { Airway } \\
\text { clamping }\end{array}$ & $\begin{array}{c}\text { At } \\
\text { excision }\end{array}$ \\
\hline I & $0-9.8 \pm 0.3$ & $0-20.6 \pm 0.8$ & $7.7 \pm 0.5$ & $7.7 \pm 0.5^{*}$ \\
\hline II & $0-8.3 \pm 0.5$ & $0-18.9 \pm 1.0$ & $6.9 \pm 0.5$ & $3.0 \pm 0.4^{*}$ \\
\hline III & $0-10.1 \pm 0.7$ & $0-20.2 \pm 1.4$ & $7.6 \pm 0.4$ & $7.6 \pm 0.4 \dagger$ \\
\hline IV & $0-8.9 \pm 0.9$ & $0-20.2 \pm 0.8$ & $7.4 \pm 0.8$ & $4.0 \pm 0.2 \dagger$ \\
\hline
\end{tabular}

${ }^{*} p<0.01$, group I versus group II.

$\ddagger p<0.01$, group III versus group IV.

times, or total ischemic times between the groups (Table I). However, airway pressures at extraction were significantly higher in groups I and III (7.7 \pm 0.5 and $7.6 \pm 0.4 \mathrm{~mm} \mathrm{Hg}$ ) compared with those in groups II and IV $(3.0 \pm 0.4$ and $4.0 \pm 0.2 \mathrm{~mm} \mathrm{Hg})$ $(p<0.01)$ (Table II). The mean time from reperfusion to initial assessment was $15.6 \pm 1.2$ minutes in group I, $14.7 \pm 1.7$ minutes in group II, $12.6 \pm 1.9$ minutes in group III, and $12.4 \pm 1.2$ minutes in group IV.

All animals tolerated the 6-hour assessment period and were available for data analysis.

Maximum airway pressure before chest closure. The maximum airway pressure in group I was significantly lower than that in group II (group I versus group II: $30.0 \pm 0.7$ versus $33.4 \pm 1.2 \mathrm{~cm} \mathrm{H}_{2} \mathrm{O} ; p<$ $0.05)$. There was no significant difference between groups III and IV (group III versus group IV: $25.0 \pm$ 1.0 versus $25.2 \pm 1.2 \mathrm{~cm} \mathrm{H}_{2} \mathrm{O}$; not significant) (Fig. $1)$.

Gas exchange during the assessment. Between groups I and II, there were significant overall differences in the trends of arterial oxygen tension $\left(\mathrm{PaO}_{2}\right)$, alveolar-arterial oxygen gradient $\left(\mathrm{A}-\mathrm{aDO}_{2}\right)$, and shunt fraction (Qs/Qt) with one-way ANOVA with repeated measures $\left(\mathrm{PaO}_{2} ; p<0.01 ; \mathrm{A}_{-}-\mathrm{aDo}_{2} ; p<\right.$ $0.01 ; \mathrm{Qs} / \mathrm{Qt} ; p<0.05$ ). Further statistical analysis at each assessment point was done. There were no significant differences in $\mathrm{PaO}_{2}$, arterial carbon dioxide tension $\left(\mathrm{PaCO}_{2}\right), \mathrm{AaD}_{2}$, or $\mathrm{Qs} / \mathrm{Qt}$ at the initial assessment. In group I, gas exchange deteriorated rapidly during assessment. Significant differences were obtained after the 135-minute assessments in $\mathrm{PaO}_{2} ; \mathrm{A}-\mathrm{aDO}_{2}$ (group I versus group II at 135-minute 

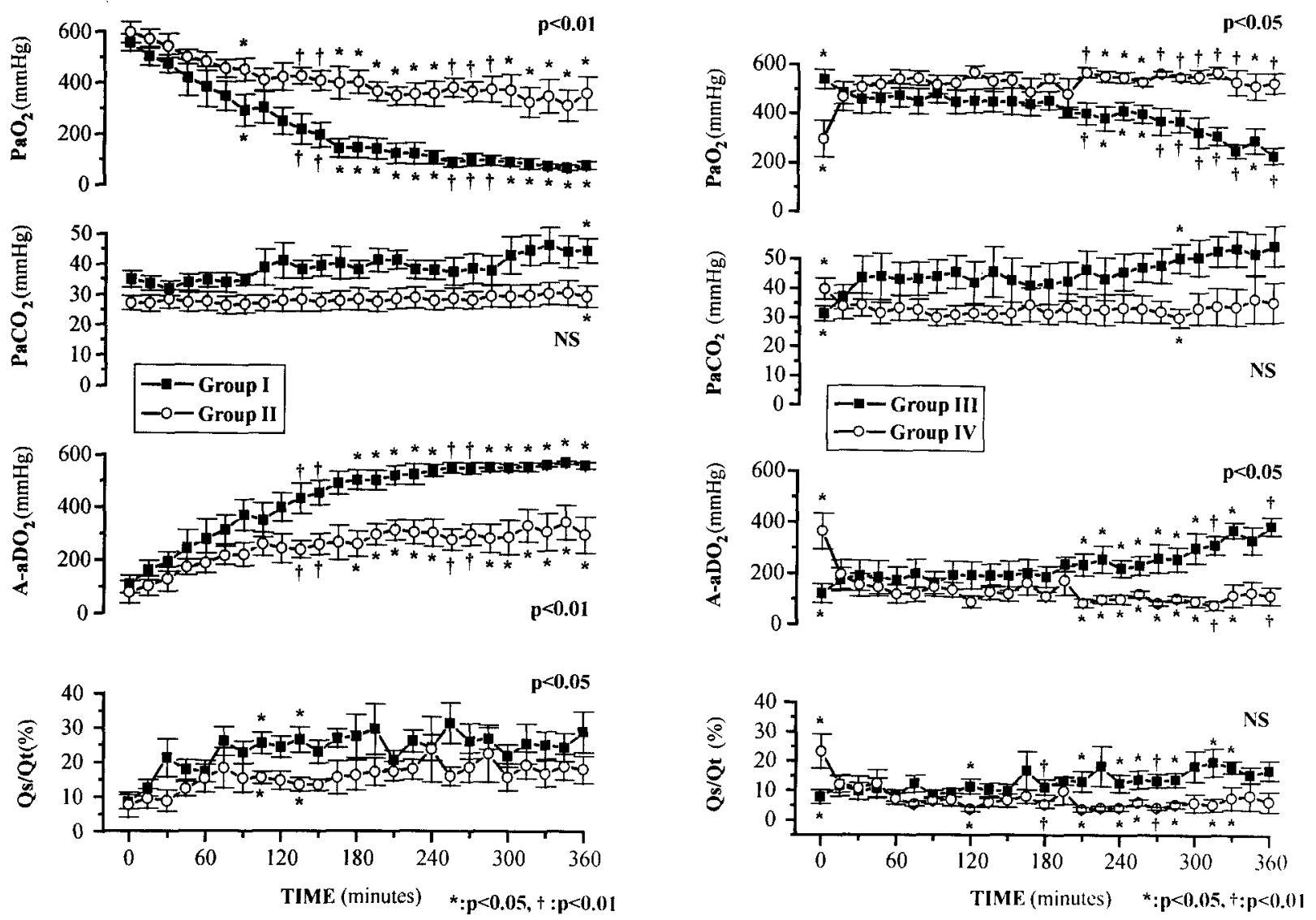

Fig. 2. Gas exchange during 6-hour assessment after ligation of right bronchi and PA (groups I and II). $p$ Values of one-way ANOVA with repeated measures between two groups are shown on right side of each parameter schema. $p$ Values for comparison at each assessment time are represented by asterisks $(p<0.05)$ and daggers $(p<0.01)$. There were no significant differences at initial assessment time between two groups in $\mathrm{PaO}_{2}, \mathrm{PaCO}_{2}, \mathrm{~A}-\mathrm{aDO}_{2}$, or Qs/Qt. However, significant differences in overall trends were observed in later assessments in $\mathrm{PaO}_{2}$ and $\mathrm{A}-\mathrm{aDO}_{2}(p<0.01)$ and in Qs/Qt $(p<0.05)$. NS, Not significant.

assessments: $\mathrm{PaO}_{2} ; 226.3 \pm 59.4$ versus $433.9 \pm 32.1$ $\mathrm{mm} \mathrm{Hg} ; \mathrm{A}-\mathrm{aDo} ; 434.5 \pm 58.3$ versus $240.3 \pm 32.8$ $\mathrm{mm} \mathrm{Hg} ; p<0.01$ ) (Fig. 2). This difference in gas exchange continued with group II animals having superior oxygenation throughout the remaining 6-hour assessment period.

Between groups III and IV, significant overall differences were detected in the trends of $\mathrm{PaO}_{2}$ and $\mathrm{A}-\mathrm{aDO}_{2}$ with one-way ANOVA with repeated measures $\left(\mathrm{PaO}_{2}, p<0.05 ; \mathrm{A}-\mathrm{aDO}_{2}, p<0.05\right)$. Further statistical analysis at each assessment point revealed that at the initial assessment, $\mathrm{PaO}_{2}$ in group IV was

Fig. 3. Gas exchange during 6-hour assessment after ligation of right PA (groups III and IV). At initial assessment, gas exchange of group III was significantly better than that of group IV $(p<0.05)$. However, gas exchange of group IV improved before second assessment and there was no significant difference between two groups. After 210-minute assessment, group III exhibited deterioration of gas exchange and significant differences in overall trends were obtained in $\mathrm{PaO}_{2}$ and $\mathrm{A}-\mathrm{aDO}_{2}(p<0.05) . N S$, Not significant.

significantly lower and $\mathrm{PaCO}_{2}, \mathrm{~A}-\mathrm{aDO}_{2}$, and $\mathrm{Qs} / \mathrm{Qt}$ in group IV were significantly higher than in group III (group III versus group IV at the initial assessment; $\mathrm{PaO}_{2}, 543.1 \pm 39.4$ versus $298.8 \pm 74.0 \mathrm{~mm} \mathrm{Hg}$; $\mathrm{PaCO}_{2}, 30.6 \pm 2.0$ versus $40.3 \pm 3.3 \mathrm{~mm} \mathrm{Hg} ; \mathrm{A}-\mathrm{aDO}_{2}$, $122.1 \pm 37.4$ versus $365.7 \pm 70.7 \mathrm{~mm} \mathrm{Hg}$; Qs/Ot, $7.9 \% \pm 2.3 \%$ versus $23.3 \% \pm 5.7 \% ; p<0.05$ ). This initial poor gas exchange in group IV improved within 15 minutes. During the subsequent 3 hours, gas exchange was similar and quite adequate in groups III and IV. After 210 minutes, gas exchange in group III began to deteriorate creating a significant difference between groups that persisted for the remaining assessment period (Fig. 3). 

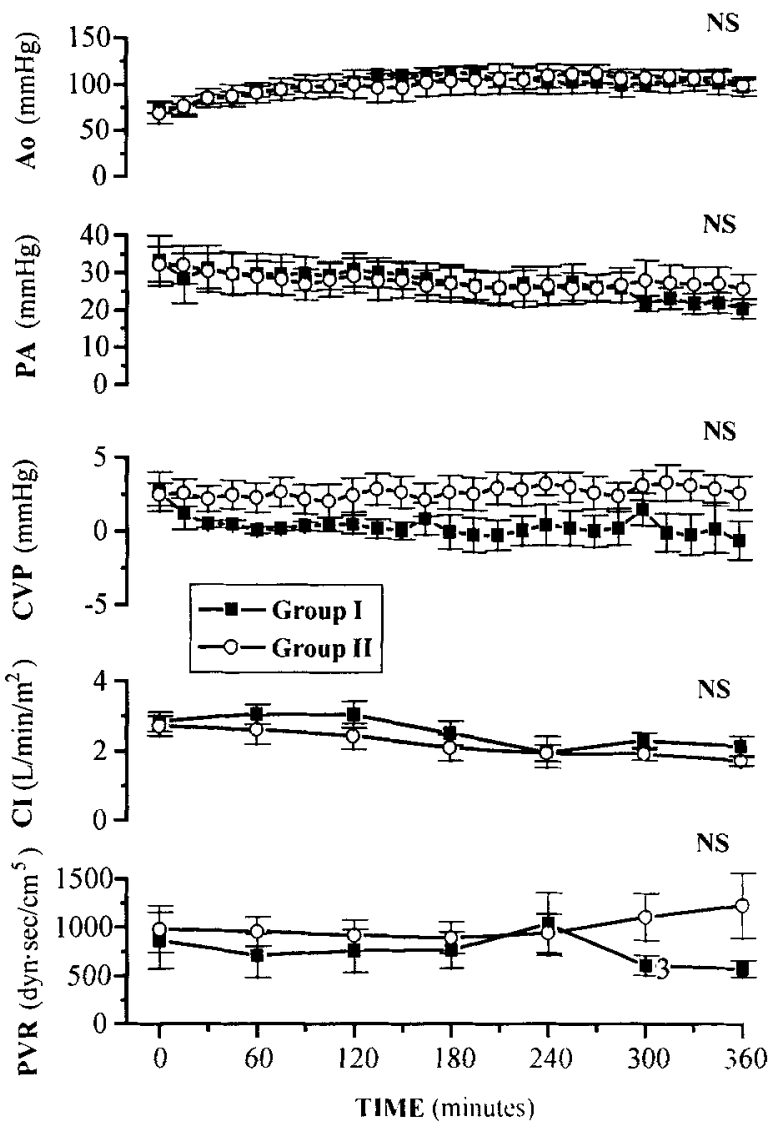

Fig. 4. Hemodynamics during 6-hour assessment after ligation of right bronchi and PA (groups I and II). There were no significant differences between two groups in aortic pressure $(A o)$, pulmonary arterial pressure $(P A)$, central venous pressure $(C V P)$, cardiac index $(C I)$, or pulmonary vascular resistance (PVR). $N S$, Not significant.

Hemodynamics. Between groups I and II, no significant differences were detected in aortic pressure, mean PA pressure, central venous pressure, cardiac index, or pulmonary vascular resistance with one-way ANOVA with repeated measures or contrast (Fig. 4).

Between groups III and IV, although significant differences were detected in mean PA pressure at the initial and 210-, 225-, and 255-minute assessments and in pulmonary vascular resistance at the initial assessment, there were no significant differences in the overall trends of aortic pressure, mean PA pressure, central venous pressure, cardiac index, or pulmonary vascular resistance (Fig. 5).

Wet/dry lung weight ratio. In groups I and II, the wet/dry lung weight ratio of the allografts was significantly higher than that of the native right
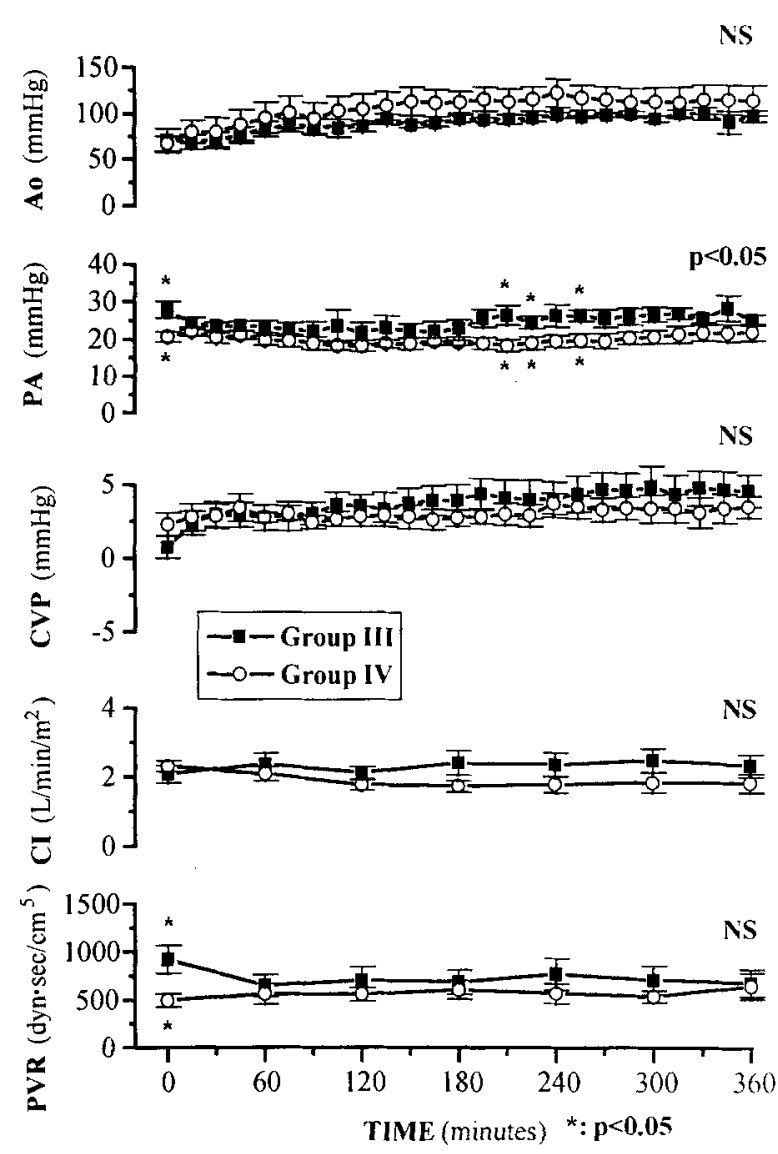

Fig. 5. Hemodynamics during 6-hour assessment after ligation of right PA (groups III and IV). There were no significant differences between two groups except in PA pressure at several times $(p<0.05)$. Abbreviations same as in Fig. 4.

lungs (right lung versus left lung in group I: $5.06 \pm$ 0.18 versus $8.67 \pm 0.63, p<0.01$; in group II: $5.33 \pm$ 0.13 versus $7.84 \pm 0.42, p<0.01$ ), but there was no significant difference between the allografts in groups I and II (Fig. 6).

Whereas wet/dry lung weight ratio for allografts was significantly higher than that of the right native lungs in group III, there was no such significant difference in group IV (the right lung versus the left lung in group III: $5.67 \pm 0.25$ versus $8.38 \pm 0.53, p<0.01$; in group IV: $6.02 \pm 0.50$ versus $6.82 \pm 0.32$, not significant). Thus there was a significant difference between allografts in groups III and IV $(p<0.05)$ (Fig. 6).

Total volume of airway edema fluid. Airway edema fluid was obtained from all of the group I and II animals. Total volume of airway edema fluid in group I was significantly greater than that in group 


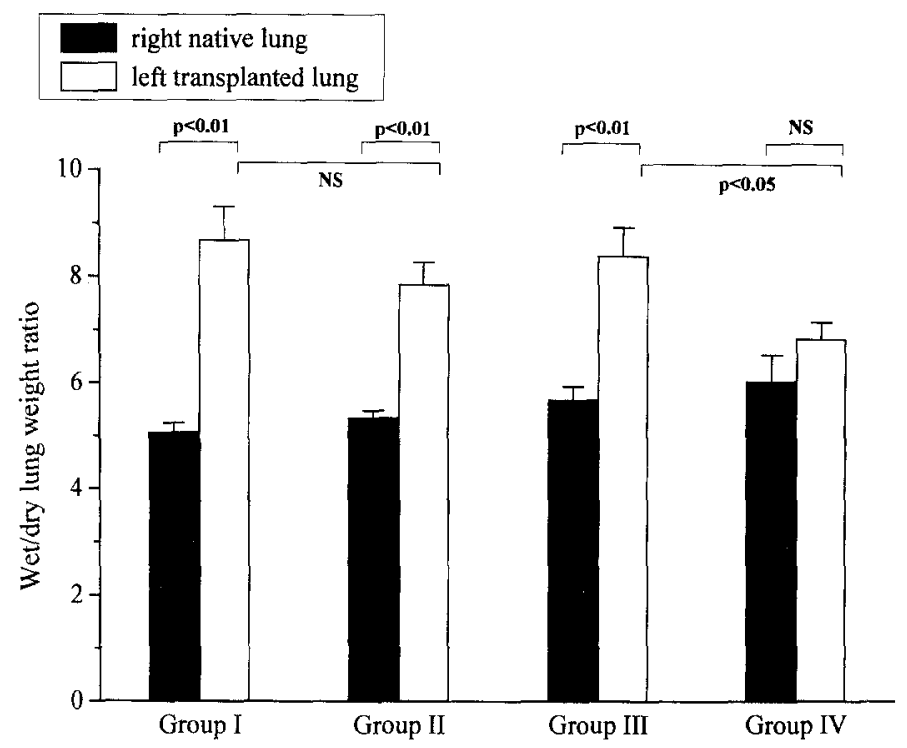

Fig. 6. Wet/dry lung weight ratio after 6-hour assessment. After assessment, wet/dry weight ratio of allograft became significantly higher than that of right native lung in groups I, II, and III $(p<0.01)$. However, wet/dry weight ratio of left transplanted lung in group IV remained same as that of nonreperfused right native lung. Thus there was significant difference between left lungs in groups III and IV $(p<0.05)$. NS, Not significant.

II (group I versus group II: $940 \pm 179$ versus $193 \pm$ $126 \mathrm{ml}, p<0.01$ ) (Fig. 7). Two of five animals in group II and all group IV animals had no measurable edema fluid during the 6-hour assessment. Therefore no statistical comparison was made between groups III and IV.

Histologic findings. After the 6-hour assessment, the transplanted left lung in all groups showed varying degrees of edema formation. No qualitative differences were detected between the groups. The right native lungs in groups I and II showed complete atelectasis and those in groups III and IV normal alveolar structure.

\section{Discussion}

Puskas and associates ${ }^{7}$ recently reported that increased ventilation volume during donor lung flush and hyperinflation during storage provide excellent preservation even in the absence of the vasodilator prostaglandin $E_{1}$. We have demonstrated that graft hyperinflation during storage prevents the accumulation of serum protein in the alveolar space, maintains surface activity, and improves early postoperative lung function. ${ }^{8}$ It might therefore be assumed that hyperinflation during storage improves early lung allograft function.

On the other hand, several studies have shown that excessive hyperdistension of the lung by either static inflation, high tidal volume, or positive endexpiratory pressure increases lung solute permeability $^{10,12}$ and produces pulmonary microvascular injury ${ }^{11}$ and pulmonary edema. ${ }^{8,9}$ Furthermore, we noted that the application of donor lung hyperinflation in a recent series of clinical lung transplants resulted in an increased prevalence of early allograft dysfunction as a result of pulmonary edema.

The canine left single-lung transplantation model with temporary contralateral PA occlusion, used by Puskas and colleagues ${ }^{7}$ and in our previous study (Aoe and colleagues, unpublished data), was originally described by Jones and associates ${ }^{13}$ in 1988. In that model, the contralateral PA is occluded temporarily with an inflatable cuff implanted around the right $\mathrm{PA}$, which thereby directs blood flow to the transplanted left lung. Hence both the transplanted left lung and the native right lung, which has a normal pulmonary vascular resistance, are perfused for most of the posttransplantation period. Yet in the clinical situation of single-lung transplantation for pulmonary hypertension, or during explantation and implantation of the second lung in bilateral lung transplantation, a single allograft will receive most if not all of the cardiac output. Indeed, even when single-lung transplantation is used in emphysema or 


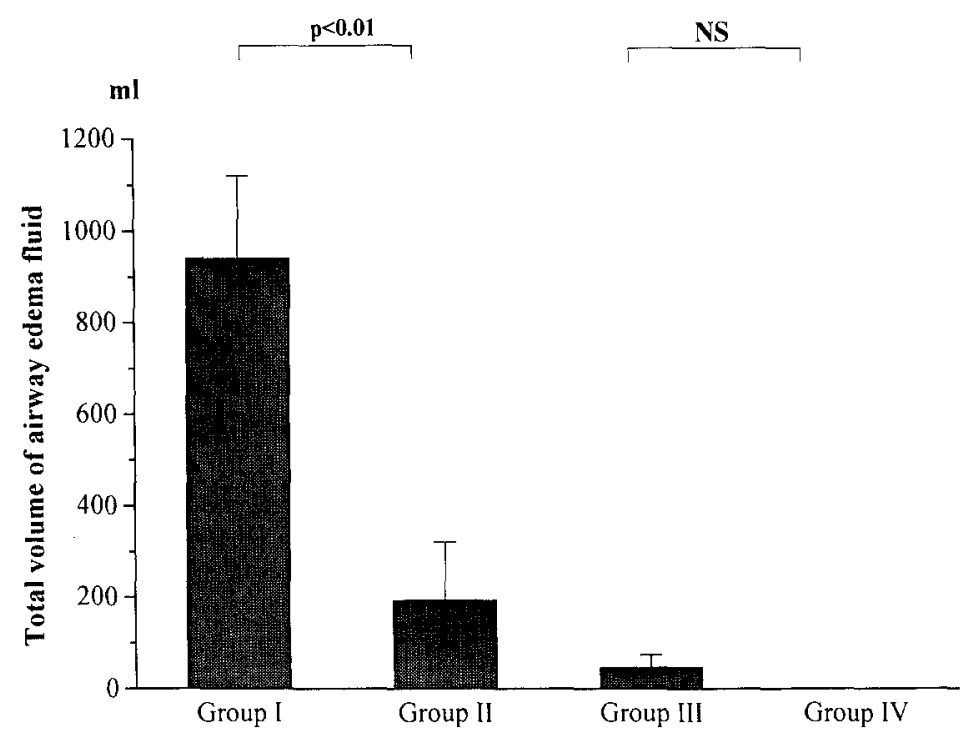

Fig. 7. Total volume of airway edema fluid suctioned during assessment. In general, one-lung ventilation groups (groups I and II) had more edema fluid production than double-lung ventilation groups (groups III and IV). There was significant difference between groups I and II $(p<0.01)$. NS, Not significant.

pulmonary fibrosis, the majority of cardiac output is directed to the allograft. In this situation a hyperventilation-induced permeability lesion would become evident. However, in the canine model used by Puskas and colleagues ${ }^{7}$ and by us (Aoe and colleagues, unpublished data), the temporary 10minute PA occlusion may permit underestimation of the permeability lesion.

Another problem with previous reports that used temporary balloon occlusion of the contralateral PA is the measurement of pulmonary capillary wedge pressure by balloon-tipped catheter inflation. With all flow to the allograft, balloon inflation in the allograft PA might give erroneous measurements of wedge pressure as a result of hemodynamic instability during balloon inflation. ${ }^{14}$ Although we have used this technique in previous studies, ${ }^{15}$ in the present study, a Millar Mikro-Tip catheter pressure transducer was introduced into the left atrium through the mediastinal pulmonary vein. This made it possible to obtain continuous and reliable values of left atrial pressure directly.

This current study demonstrates that immediate postpreservation lung function is satisfactory irrespective of the state of inflation during storage. However, gas exchange in the hyperinflated lungs deteriorated within the early reperfusion period and was significantly worse than that in lungs stored at normal volume. In this study we have also demonstrated that with both native and transplanted lungs ventilated and only the transplanted lung perfused, immediate function of hyperinflated lungs was satisfactory but once again deteriorated as transplanted lungs became edematous during the latter portion of the 6-hour reperfusion period. Allografts stored in a state of normal inflation appeared to have lower pulmonary compliance with ventilation preferentially directed to the native right lung during the initial phase of assessment. This may explain the initially poor gas exchange in group IV animals. However, once the transplanted lung became well ventilated it maintained adequate pulmonary function throughout the 6-hour assessment period.

The decision to use a tidal volume of $750 \mathrm{ml}$ to hyperinflate lungs at harvest was based on the report of Fonkalsrud and colleagues ${ }^{4}$ that lungs inflated with static $10 \mathrm{~cm}$ of water pressure provided superior preservation compared with lungs inflated with $25 \mathrm{~cm}$ of water pressure. Our previous study showed that a tidal volume of $750 \mathrm{ml}$ was adequate to obtain a static inflation pressure of approximately $10 \mathrm{~cm}$ of water pressure (approximately $6 \mathrm{~mm} \mathrm{Hg}$; Aoe and colleagues, unpublished data). Additionally, that study revealed no microscopic lung parenchymal damage from such a tidal volume during the harvest procedure.

Air withdrawal after flushing in groups II and IV (normoinflation groups) was done to make the lungs more normally inflated and to create a significant difference in intraairway pressure between the 
groups. It should be emphasized that air was withdrawn gently under positive pressure to avoid uneven withdrawal and local microatelectasis. Lungs of the normoinflation groups were visibly smaller than the lungs of the hyperinflation groups stored after inflation with a tidal volume of $750 \mathrm{ml}$. Yet lungs from the normoinflation groups maintained a normal state of inflation during preservation and had no apparent local atelectasis on gross and microscopic examination.

It has been reported that preserved lungs maintain aerobic metabolism during storage and produce carbon dioxide ${ }^{16}$ that replaces intraalveolar oxygen and dissolves into the flushing solution. ${ }^{17}$ Haniuda and associates ${ }^{12}$ demonstrated that donor lungs have a volume decrease during storage. Although some decrease in lung volume is inevitable, we have observed that, even 24 hours after harvest, no microatelectasis was found in the preserved lungs that had $200 \mathrm{ml}$ of air withdrawn at harvest (Aoe and colleagues, unpublished data).

In the current study during the 6-hour assessment period we chose to use high tidal volumes of $550 \mathrm{ml}$ in groups I and II (single lung ventilation) and 750 $\mathrm{ml}$ in groups III and IV (bilateral lung ventilation). This degree of hyperventilation was used to avoid acidosis. Acidosis will increase PA pressure and adversely affect graft function. Correction of $\mathrm{pH}$ solely by bicarbonate administration can require a large volume of fluid infusion and increase central venous pressure resulting in pulmonary edema and allograft dysfunction.

The model used in this study provides a severe test of allograft function. The ischemic time used is longer than the 6- to 8-hour ischemia acceptable in clinical lung transplant programs. Prolonged contralateral PA occlusion is capable of detecting a permeability defect that is not evident with shorter periods of temporary PA occlusion. The findings of the current study indicate that hyperinflation during storage is detrimental to subsequent allograft function. On the basis of these results, we no longer use hyperinflation in clinical lung harvests but rather harvest and store donor lungs in a state of normal end tidal inspiration.

We acknowledge the expert technical assistance of Donna Marquart, Timothy Morris, Dennis Gordon, Steven Labarbera, and Duane Probst and the secretarial support of Dawn Schuessler and Mary Ann Kelly. Preservation solutions were provided by Gary Queensen, RPh.
Statistical advice was obtained from Richard B. Schuessler, PhD.

\section{REFERENCES}

1. Patterson GA, Cooper JD, eds. Lung transplantation. Vol. 3 , no. 1. Philadelphia; WB Saunders, 1993.

2. Homatas J, Bryant L, Eiseman B. Time limits of cadaver lung viability. J Thorac Cardiovasc Surg 1968;56:132-40.

3. Veith FJ, Sinha SB, Graves JS, Boley SJ, Dougherty JC. Ischemic tolerance of the lung: the effect of ventilation and inflation. J Thorac Cardiovasc Surg 1971;61:804-10.

4. Fonkalsrud EW, Sanchez M, Lassaletta L, Smeesters C, Higashijima I. Extended preservation of the ischemic canine lung by ventilation with PEEP. J Surg Res 1975;18:437-45.

5. Fonkalsrud E, Sanchez M, Higashijima I, Gyepes M, Arima E. Evaluation of pulmonary function in the ischemic expanded canine lung. Surg Gynecol Obstet 1976;142:573-7.

6. Todd TR, Goldberg M, Koshal A, Menkis A, Boychuk J, Patterson GA, et al. Separate extraction of cardiac and pulmonary grafts from a single organ donor. Ann Thorac Surg 1988;46:356-9.

7. Puskas JD, Hirai T, Christie N, Mayer E, Slutsky AS, Patterson GA. Reliable thirty-hour lung preservation by donor hyperinflation. J Thorac Cardiovasc Surg 1992;104: 1075-83.

8. Webb HH, Tierney DF. Experimental pulmonary edema due to intermittent positive pressure ventilation with high inflation pressure: protection by positive end-expiratory pressure. Am Rev Respir Dis 1974;110:556-65.

9. Eagan EA. Lung inflation, lung solute permeability, and alveolar edema. J Appl Physiol 1982;53:121-5.

10. Parker JC, Townsley MI, Rippe B, Taylor AE, Thigpen J. Increased microvascular permeability in dog lungs due to high peak airway pressure. J Appl Physiol 1984;57:1809-16.

11. Dreyfuss D, Basset G, Soler P, Saumon G. Intermittent positive-pressure hyperventilation with high inflation pressure produces pulmonary microvascular injury in rats. Am Rev Respir Dis 1985;132:880-4.

12. Haniuda M, Hasegawa S, Shiraishi T, Dresler CM, Cooper JD, Patterson GA. Effects of inflation volume during lung preservation on pulmonary capillary permeability. J Thorac Cardiovasc Surg 1996;112:85-93

13. Jones MT, Hsieh C, Yoshikawa K, Patterson GA, Cooper JD. A new model for assessment of lung preservation. J Thorac Cardiovasc Surg 1988;96:608-14.

14. Wittnich C, Trudel J, Zidulka A, Chiu RCJ. Misleading "pulmonary wedge pressure" after pneumonectomy: its importance in postoperative fluid therapy. Ann Thorac Surg 1986;42:192-6.

15. Aoe M, Trachiotis GD, Okabayashi $\mathrm{K}$, et al. Administration of prostaglandin $\mathrm{E}_{1}$ following lung transplantation improves early graft function. Ann Thorac Surg 1994;58:655-61.

16. Date H, Matsumura A, Manchester JK, Cooper JM, Lowry $\mathrm{OH}$, Cooper JD. Changes in alveolar oxygen and carbon dioxide concentration and oxygen consumption during lung preservation: the maintenance of aerobic metabolism during lung preservation. J Thorac Cardiovasc Surg 1993;105:492501.

17. Shepard JW Jr, Dolan GF. Transpleural $\mathrm{CO}_{2}$ diffusion in excised dog lungs. Respir Physiol 1983;52:205-16. 